\title{
FORMAÇÃO DE PROFESSORES PARA A EDUCAÇÃO PROFISSIONAL E TECNOLÓGICA A DISTÂNCIA DA REDE FEDERAL DE EDUCAÇÃO BRASILEIRA: ANÁLISE DAS PRODUÇÕES ACADÊMICAS
}

\author{
R. PASQUALLI ${ }^{1 *}$, J. A. VIEIRA ${ }^{2}$ e M. M. M. VIEIRA ${ }^{2}$ \\ ${ }^{1}$ Instituto Federal de Educação, Ciência e Tecnologia de Santa Catarina \\ ${ }^{2}$ Instituto Federal de Educação, Ciência e Tecnologia do Rio Grande do Sul \\ rpasqualli@gmail.com *
}

Artigo submetido em outubro/2015 e aceito em dezembro/2015

DOI: $10.15628 /$ rbept.2015.3558

\section{RESUMO}

Com o olhar atento para as propostas da Rede e-Tec Brasil, observa-se que a ampliação da oferta de cursos e vagas por meio da modalidade de educação a distância (EAD) tem levado para as salas de aulas, presenciais ou virtuais, um número expressivo de bacharéis docentes, com formação técnica, atendendo ao que demandam os editais de contratação de professores, mas com pouca ou nenhuma formação pedagógica para o exercício da atividade docente a distância. Sendo assim, o presente artigo buscou catalogar as produções acadêmicas dos últimos seis anos acerca da formação de professores para a educação profissional e tecnológica (EPT) a distância na Rede Federal de Educação Brasileira, apresentados em Programas de Pós-Graduação Stricto Sensu e em eventos científicos. Constatou-se a quase inexistência de pesquisas relacionadas à problemática anunciada. Timidamente surgem trabalhos que iniciam discussões sobre a formação de professores para a EPT e em maior proporção para a EAD. Indica-se a urgência de que se aprofundem as discussões e pesquisas acerca desta temática.

PALAVRAS-CHAVE: Formação de Professores, EPT, Educação a Distância.

\section{TEACHER TRAINING FOR VOCATIONAL EDUCATION AND TECHNOLOGICAL DISTANCE EDUCATION FEDERAL NETWORK BRAZIL: ANALYSIS OF PRODUCTIONS ACADEMIC}

\begin{abstract}
With the look out for the proposals of the Network e-Tec Brazil, it is observed that the expansion of supply of courses and places through the distance education mode (EAD) has led to the classrooms, or virtual one significant number of graduates teachers with technical training, given the demanding teacher recruitment notices, but with little or no pedagogical training for the teaching practice the distance. Thus, this paper aims to catalog the academic productions of the past six years on the training
\end{abstract}

of teachers for vocational and technological education (EPT) the distance in the Federal Brazilian Education Network, presented in the Graduate Programs Stricto Sensu and events scientific. It found there are hardly any research related to the announced issue. Timidly arise jobs that start discussions on the training of teachers for EPT and to a greater extent to the EAD. Indicates the urgency that more detailed discussions and research on this subject.

KEYWORDS: Teacher Training, EPT, Distance Education. 


\section{CONTEXTUALIZANDO O LÓCUS DA PESQUISA}

Em dezembro de 2008 foi instituída, por meio da Lei ${ }^{\circ}{ }^{11}$ 11.892, a Rede Federal de Educação Profissional, Científica e Tecnológica. A rede é composta pelos Institutos Federais de Educação, Ciência e Tecnologia (IFs), pela Universidade Tecnológica Federal do Paraná (UTFPR), pelos Centros Federais de Educação Tecnológica Celso Suckow da Fonseca (CEFETRJ) e de Minas Gerais (CEFETMG) e pelas Escolas Técnicas Vinculadas às Universidades Federais. De acordo com informações da Secretaria de Educação Profissional e Tecnológica do Ministério da Educação (MEC/SETEC), até maio de 2015, a Rede Federal contava 38 IFs presentes em todos os Estados da União, perfazendo um total de 354 instituições públicas trabalhando com educação profissional e tecnológica pública no país.

De acordo com o Art. $2^{\circ}$ de sua Lei de criação, "os Institutos Federais são instituições de Educação Superior, Básica e Profissional, pluricurriculares e multicampi, especializados na oferta de educação profissional e tecnológica nas diferentes modalidades de ensino, com base na conjugação de conhecimentos técnicos e tecnológicos com as suas práticas pedagógicas".

De acordo com o Art. 6으, os Institutos Federais têm por finalidades e características:

I - ofertar educação profissional e tecnológica, em todos os seus níveis e modalidades, formando e qualificando cidadãos com vistas na atuação profissional nos diversos setores da economia, com ênfase no desenvolvimento socioeconômico local, regional e nacional;

II - desenvolver a educação profissional e tecnológica como processo educativo e investigativo de geração e adaptação de soluções técnicas e tecnológicas às demandas sociais e peculiaridades regionais;

III - promover a integração e a verticalização da educação básica à educação profissional e educação superior, otimizando a infraestrutura física, os quadros de pessoal e os recursos de gestão;

IV - orientar sua oferta formativa em benefício da consolidação e fortalecimento dos arranjos produtivos, sociais e culturais locais, identificados com base no mapeamento das potencialidades de desenvolvimento socioeconômico e cultural no âmbito de atuação do Instituto Federal;

$V$ - constituir-se em centro de excelência na oferta do ensino de ciências, em geral, e de ciências aplicadas, em particular, estimulando o desenvolvimento de espírito crítico, voltado à investigação empírica;

VI - qualificar-se como centro de referência no apoio à oferta do ensino de ciências nas instituições públicas de ensino, oferecendo capacitação técnica e atualização pedagógica aos docentes das redes públicas de ensino;

VII - desenvolver programas de extensão e de divulgação científica e tecnológica;

VIII - realizar e estimular a pesquisa aplicada, a produção cultural, o empreendedorismo, o cooperativismo e o desenvolvimento científico e tecnológico;

IX - promover a produção, o desenvolvimento e a transferência de tecnologias sociais, notadamente as voltadas à preservação do meio ambiente. 
Os IFs são conhecidos por atuar em todos os níveis e modalidades de educação profissional, visando ofertar uma estrutura lógica de formação humana e profissional, não sendo apenas um amontoado de cursos sem ligações entre si. Destaca-se, em suas ações, a promoção da justiça social, da equidade e do desenvolvimento sustentável, com vistas a soluções técnicas e geração de novas tecnologias, respondendo às demandas a eles apresentados de forma ágil e eficaz, enfatizando a formação profissional, a difusão de conhecimentos científicos e o suporte aos arranjos produtivos locais.

Uma vez que os IFs são o lócus da pesquisa, o artigo da lei que particularmente nos interessa é o $7^{\circ}$, incisos I, II e VI, pois afirmam ser finalidades e características dos IFs: "ministrar educação profissional técnica de nível médio, prioritariamente na forma de cursos integrados, para os concluintes do ensino fundamental e para o público da educação de jovens e adultos"; "ministrar cursos de formação inicial e continuada de trabalhadores, objetivando a capacitação, o aperfeiçoamento, a especialização e a atualização de profissionais, em todos os níveis de escolaridade, nas áreas da educação profissional e tecnológica" e "ministrar em nível de educação superior [...].".

No que diz respeito à educação a distância (EAD), destaca-se que, mais de uma década antes da criação dos IFs, a Lei de Diretrizes e Bases da Educação Nacional (LDB), em seu artigo 80, já garantia a sua oferta por meio do poder público em todos os níveis e modalidades de ensino e, em 2007, mesmo antes da criação da Rede Federal de Educação Profissional, Científica e Tecnológica, o decreto no 6301/2007 instituiu o Sistema Escola Técnica Aberta do Brasil - e-Tec Brasil, o qual foi revogado pelo decreto $n=7589 / 2011$. O decreto $n=7589 / 2011$ que institui a Rede e-Tec Brasil, é uma das ações que integram o Programa Nacional de Acesso ao Ensino Técnico e Emprego (PRONATEC) e tem como finalidade oferecer, na modalidade de educação a distância, por meio da proposta de verticalização de ensino apresentada pela Rede de Educação Profissional e Tecnológica (EPT) cursos de formação inicial e continuada (FIC), cursos de ensino técnico nas modalidades integrado ao ensino médio, concomitante e subsequente ao ensino médio, cursos superiores de tecnologia e cursos de pós-graduação.

De acordo com o artigo 3ำ do seu decreto de criação, os objetivos da Rede e-Tec são:

I - estimular a oferta da educação profissional e tecnológica, na modalidade a distância, em rede nacional;

II - expandir e democratizar a oferta da educação profissional e tecnológica, especialmente para o interior do País e para a periferia das áreas metropolitanas;

III - permitir a capacitação profissional inicial e continuada, preferencialmente para os estudantes matriculados e para os egressos do ensino médio, bem como para a educação

de jovens e adultos;

IV - contribuir para o ingresso, permanência e conclusão do ensino médio por jovens e adultos;

$V$ - permitir às instituições públicas de ensino o desenvolvimento de projetos de pesquisa e de metodologias educacionais em educação a distância na área de formação inicial e continuada de docentes para a educação profissional e tecnológica; 
$\mathrm{VI}$ - promover o desenvolvimento de projetos de produção de materiais pedagógicos

e educacionais para a formação inicial e continuada de docentes para a educação profissional e tecnológica;

VII - promover junto às instituições públicas de ensino o desenvolvimento de projetos de produção de materiais pedagógicos e educacionais para estudantes da educação profissional e tecnológica; e

VIII - permitir o desenvolvimento de cursos de formação inicial e continuada de docentes, gestores e técnicos administrativos da educação profissional e tecnológica, na modalidade de educação a distância.

Apresentado o lócus da pesquisa, apresentamos discussões sobre os aspectos legais da atividade docente na educação profissional e tecnológica a distância brasileira.

\section{A ATIVIDADE DOCENTE: A LEGALIDADE E AS DEMANDAS COTIDIANAS}

Do ponto de vista legal, de modo a iniciar a discussão acerca dos saberes fundamentais para o exercício da docência na educação profissional e tecnológica a distância, cabe destacar a formação acadêmica requerida para atuar em cada um destes níveis:

O exercício da docência na Educação Básica possui amparo legal no artigo 62 da LDB 9394/96 e apresenta as seguintes exigências:

A formação de docentes para atuar na Educação Básica far-se-á em nível Superior, em curso de Licenciatura, de Graduação Plena, em Universidades e Institutos Superiores de Educação, admitida, como formação mínima para o exercício do magistério na educação infantil e nas quatro primeiras séries do ensino fundamental, a oferecida em nível médio, na modalidade normal.

No caso dos cursos de licenciatura, existe a compreensão de que a formação pedagógica se dá ao longo da caminhada formativa, já que é um curso de formação de professores e contém em sua matriz curricular carga horária destinada obrigatoriamente a componentes curriculares pedagógicos e práticas de estágios.

Para o Ensino Superior, a legalidade da atuação docente também é dada pela LDB 9394/96, no seu Artigo 52, quando estabelece que um terço do corpo docente, pelo menos, tenha titulação acadêmica Mestrado ou Doutorado, ou seja, um em cada três docentes que atuam em cada curso superior (núcleo docente estruturante) necessita obrigatoriamente possuir o título de Mestre ou Doutor.

Entretanto, a Pós-Graduação Stricto Sensu, tida como o lócus privilegiado de estudos científicos, tende a priorizar a pesquisa e a publicação científica, perpetuando, embora muitas vezes não intencionalmente, o imaginário de que para ser bom professor basta conhecer profundamente a teoria acerca do que vai ensinar, incluindo também os bons relacionamentos com a comunidade científica e seu notório reconhecimento como pesquisador. Ainda hoje se acredita, como afirma Masetto (1998, p. 11), quando critica esse senso comum, que "quem soubesse, saberia automaticamente ensinar", sem que haja uma preparação pedagógica para assumir um papel que possui grande parcela de natureza pedagógica. 
Na educação profissional e tecnológica não é diferente. Durante muito tempo a formação necessária para os professores que atuavam nesta modalidade de educação foi dada como algo indiscutível: para ensinar bastava saber fazer. Apesar das drásticas mudanças na sociedade e no mundo do trabalho, de alguns sinais de mudanças que se avizinham, ainda se observa que hoje prevalece presença de professores sem formação inicial ou continuada para a docência na educação, predominando a concepção de que o domínio do conhecimento da área técnica é suficiente para tornar-se professor.

Para Oliveira (2006), o professor do ensino técnico não é considerado um profissional da educação. Ele é um profissional de uma área específica que também leciona. A autora aponta também como obstáculo ao reconhecimento da docência como profissão que:

[...] as áreas técnicas não contam com um corpo de estudos razoavelmente denso que, tendo por objetivos a pesquisa da prática pedagógica dos seus professores e da prática profissional, no mercado de trabalho, auxilie o entendimento epistemológico do ensino nessas áreas e a pedagogização do saber a elas correspondente. (2010, p. 470).

Tentativas de rompimento com a dicotomia professor profissional da educação versus professor profissional da área técnica vêm ocorrendo nos últimos anos, já que a temática tem sido foco de estudos e discussões que apontam para uma revisão da compreensão da prática pedagógica do professor, concebido como mobilizador de diferentes saberes. O saber docente, como afirma Tardif (2007, p. 36), é "um saber plural, formado pelo amálgama, mais ou menos coerente, de saberes oriundos da formação profissional e de saberes disciplinares, curriculares e experienciais". Os saberes estão presentes no cotidiano e obrigam todos os docentes a dialogar com o sentido de que, se docente, não se pode ser neutro.

O conhecimento do professor não é meramente acadêmico, racional, feito de fatos, noções e teorias, como também não é um conhecimento feito só de experiência. É um saber que consiste em gerir a informação disponível e adequála estrategicamente ao contexto da situação formativa em que, em cada instante, se situa sem perder de vista os objetivos traçados. É um saber agir em situação. Mas não se fique com uma ideia pragmático-funcionalista do papel do professor na sociedade, porque o professor tem de ser um homem ou uma mulher de cultura, ser pensante e crítico, com responsabilidades sociais no nível de construção e do desenvolvimento da sociedade (ALARCÃO, 1998, p. 104).

A atuação docente na EAD é orientada pela legislação da educação presencial. Entretanto, ao contrário da desta, que é ofertada, em sua maioria, por docentes concursados, na EAD, boa parte de sua oferta se dá por meio dos programas Universidade Aberta do Brasil (UAB) e Rede eTec, que têm seu funcionamento dado por meio da Resolução CD/FNDE no 18, de 16 de junho de 2010, estabelecendo orientações e diretrizes para concessão e pagamento de bolsas de estudo e pesquisa. Estas, por sua vez, determinam os cargos e funções e a qualificação necessária para a atuação, que não ultrapassa a exigência mínima de curso superior e experiência de um a três anos de docência ou mesmo curso superior e vinculação em programa de pós-graduação de mestrado ou doutorado (dependendo da função) o que, no caso da educação profissional e tecnológica, traz à tona dois problemas: a falta de formação para a docência e para a docência em EAD. 
No que diz respeito às discussões acerca da formação de professores para EAD, desde 2001, Litwin com o olhar em Shulman (1995) já afirmava que os saberes básicos de um professor da EAD incluíam pelo menos os conhecimentos do professor da educação presencial, ou seja, conhecimentos do conteúdo, conhecimento pedagógico de tipo real, especialmente no que diz respeito às estratégias e à organização da classe; conhecimento curricular; conhecimento pedagógico acerca do conteúdo; conhecimento sobre os contextos educacionais; e conhecimento das finalidades, dos propósitos e dos valores educativos e de suas raízes históricas e filosóficas. Hoje podemos afirmar que a estes saberes é fundamental acrescer os saberes da natureza da modalidade de EAD, do uso adequado das tecnologias digitais, do estar junto-virtual, da cibercultura, entre outros.

É na busca por respostas para estes dois problemas que a pesquisa se encaminha, buscando discussões sobre a temática central da pesquisa: a formação de professores da educação profissional e tecnológica a distância da Rede Federal de Educação Brasileira.

\section{DO MÉTODO AOS RESULTADOS: FORMAÇÃO DE PROFESSORES PARA A EDUCAÇÃO PROFISSIONAL E TECNOLÓGICA A DISTÂNCIA DA REDE FEDERAL DE EDUCAÇÃO BRASILEIRA}

O trabalho caracteriza-se pela abordagem qualitativa constituída de pesquisa documental. A constituição desse tipo de estudo, segundo Haddad (2002, p. 9), “[...] permite, num recorte temporal definido, sistematizar um determinado campo do conhecimento, reconhecer os principais resultados da investigação, identificar temáticas e abordagens dominantes e emergentes, bem como lacunas e campos inexplorados abertos a pesquisas futuras".

Foram localizadas e analisadas as produções acadêmicas produzidas nos últimos seis anos que constam, no período (2009-2014), nas seguintes fontes:

a) Banco de Teses e Dissertações da CAPES - Coordenação de Aperfeiçoamento de Pessoal de Nível Superior;

b) Biblioteca Digital Brasileira de Teses e Dissertações - BDTD, do Instituto Brasileiro de Informação em Ciência e Tecnologia - IBICT;

c) Trabalhos apresentados no SENEPT - Seminário Nacional de Educação Profissional e Tecnológica;

d) Reuniões da ANPED (32a a 36ạ) - Associação Nacional de Pós-Graduação e Pesquisa em Educação;

e) ENDIPE - Encontro Nacional de Didática e Prática de Ensino;

f) EDUCERE - Congresso Nacional de Educação (PUCPR);

f) Eventos da ABED - Associação Brasileira de Educação a Distância; e

g) Colóquio Nacional Educação Profissional do IFRN - Instituto Federal de Educação Federal de Educação, Ciência e Tecnologia do Rio Grande do Norte.

Entende-se que essa busca é importante, pois permite uma aproximação e familiarização com a produção do campo de pesquisa, uma vez que "[...] o encontro de novos insights precisa 
estar baseado no conhecimento á disponível" (FLICK, 2009, p. 62). A escolha por estas fontes de pesquisa deu-se em função de que os materiais produzidos pelos programas de Pós-Graduação Stricto Sensu, e eventos citados têm tido importância na circulação e difusão de ideias educacionais, e nelas, as ligadas à área de educação profissional e tecnológica, cujo tema é emergente.

As pesquisas foram realizadas de acordo com o que o repositório da fonte dos dados permitiu: seja por meio de mecanismos de busca avançada, selecionando as publicações a partir do ano de 2009, ou mesmo por busca individualizada em cada edição do evento.

Quando realizada por meio de mecanismos de busca avançada de dados, o filtro utilizado foi a função dos descritores 'Educação Profissional e Tecnológica' e 'Formação de Professores' e 'Educação a Distância'. Em um segundo momento, buscando aproximações, foram inseridas as palavras 'EAD', 'Ensino a Distância', 'EaD', 'Saberes Docentes', 'Ensino Técnico', 'Profissionalização Docente', 'Formação de Educadores', 'EPT' e 'Formação Docente'. Quando não contou com mecanismos informatizados da plataforma de dados, leitura iniciou pelos títulos de cada texto publicado, seguindo pelas palavras-chave e pelos resumos.

Iniciou-se a pesquisa pela plataforma do Banco de Teses e Dissertações da CAPES. Esta plataforma possui mecanismos de busca avançada, permitindo que a pesquisa seja realizada com a utilização de filtros. Quando os descritores 'Educação Profissional e Tecnológica' e 'Formação de Professores' e 'Educação a Distância' foram incluídos sem nenhum filtro, foram encontrados 76 títulos. Ao fazer um simples filtro, solicitando que o descritor 'Formação de Professores' estivesse selecionado como palavra-chave, o número de títulos encontrados reduziu para 10. Ao solicitar que o descritor 'Educação Profissional e Tecnológica' estivesse na palavra-chave, o número de títulos reduziu para zero.

Em um movimento de possíveis encontros com as pesquisas sobre a temática, foram feitas buscas com a junção de descritores 'EAD', 'Ensino a Distância', 'EaD', 'Saberes Docentes', 'Ensino Técnico', 'Profissionalização Docente', 'Formação de Educadores', 'EPT', com filtro de palavrachave em 'distância', chegando novamente a 76 registros que, analisados um a um, indicaram a ausência de pesquisas que tratem da formação de professores para a educação profissional e tecnológica a distância.

A base de dados da Biblioteca Digital Brasileira de Teses e Dissertações - BDTD, do Instituto Brasileiro de Informação em Ciência e Tecnologia - IBICT, também permite busca por meio de dados avançados. Durante o processo de pesquisa foram utilizados os descritores 'Educação Profissional e Tecnológica' e 'Formação de Professores' e 'Educação a Distância', para produções acadêmicas a partir do ano de 2009 onde somente foram localizados 3 trabalhos com temáticas aproximadas, mas como não pertencentes ao escopo da pesquisa, não foram avaliados.

Encerradas as pesquisas em repositórios com dados de Teses e Dissertações, passou-se para a busca em anais de eventos qualificados da área de educação que possuem grupos de trabalho com aproximação com a temática investigada.

Em relação ao Seminário Nacional de Educação Profissional e Tecnológica (SENEPT), que é um evento científico de abrangência nacional, cuja finalidade é propiciar o intercâmbio entre pesquisadores e estudantes que se dedicam as questões relativas à Ciência, Tecnologia, Educação Científica, Tecnológica e Profissional e ocorre desde 2008, os trabalhos analisados foram das 
edições de 2010, 2012 e 2014. Foram lidos todos os resumos dos trabalhos que tinham em seus títulos e palavras-chave aproximação com descritores 'Educação Profissional e Tecnológica' e 'Formação de Professores' e 'Educação a Distância'.

Apesar de apresentar diversas pesquisas sobre EAD, incluindo inovações tecnológicas, avaliação da aprendizagem, tutoria e formação e professores, não trouxe a questão em pesquisa para a discussão.

O mesmo processo analítico foi realizado para as Reuniões da ANPED (32a a 36a ) Associação Nacional de Pós-Graduação e Pesquisa em Educação, os Encontro Nacional de Didática e Prática de Ensino (ENDIPE), e os Congressos Nacional de Educação (EDUCERE- PUCPR), e nenhuma produção acadêmica foi localizada.

Os eventos da Associação Brasileira de Educação a Distância (ABED) - Congresso Internacional ABED de Educação a Distância (CIAED - 2009 até 2014), Jornada Virtual ABED de Educação a Distância (JOVAED - 20011, 2012 e 2013) e Seminário Nacional ABED de Educação a Distância (SENAED - 2009, 2011, 2013 e 2014) também foram analisados. Não houve nenhuma publicação sobre a temática em questão, mas houve, no 10 SENAED e no 20 CIAED, em 2014 o fórum - FNEaD - Fórum Nacional de Educação Profissional Técnica a Distância.

Por fim, foram analisadas todas as publicações das edições do II Colóquio Nacional Educação Profissional do IFRN (2013), uma vez que os trabalhos apresentados no I Colóquio, realizado em 2011, ainda não estão disponíveis no sítio do evento (http://portal.ead.ifrn.edu.br/coloquio-publicacoes) até o momento. Na sua segunda edição, em 2013, dos 81 trabalhos apresentados, apenas 2 possuem relação com a temática de educação a distância e uma única apresenta uma proposta próxima ao que se busca inventariar nesta pesquisa. A pesquisa "A Formação Pedagógica e a Formação em Educação Profissional e Tecnológica dos Tutores da Rede e-Tec Brasil no IFRN", apresentada por Edilene Pereira Ferreira Gomes e Hareton Ribeiro Gomes, faz um levantamento sobre os requisitos exigidos para a tutoria dos cursos técnicos de nível médio subsequentes a distância no Instituto Federal de Educação, Ciência e Tecnologia do Rio Grande do Norte (IFRN). Com base nos editais de contratação e nos projetos pedagógicos de cursos, observou-se a inexistência de formação pedagógica para atuação como tutor da EAD e questiona-se a atuação docente sem a necessária formação para tal. Propõe a criação de um curso de formação pedagógica para os professores que vão atuar como docentes da educação profissional a distância.

[...] a pesquisa aponta que devem ser feitas ações para colaborar com a formação didático-pedagógica em educação profissional e tecnológica dos tutores da Rede eTec Brasil do IFRN, principalmente os que possuem apenas nível médio, para preencher as lacunas de sua formação, e dar uma melhor qualificação em docência aos professores sem licenciatura que atuam na educação profissional do IFRN, na Rede e-Tec Brasil e na Universidade Aberta do Brasil (UAB). Para isso, o estudo sugere a construção de uma matriz curricular de referência que abranja a dimensão didático-pedagógica em docência, a dimensão da EPT e as características dos cursos técnicos na modalidade $\mathrm{EaD}$ existentes no IFRN que servirão de subsídios para a criação do Curso de Formação Pedagógica em Educação Profissional e Tecnológica (CFPEPT) para o exercício da docência em EPT na modalidade à distância do Sistema Rede e-Tec Brasil no IFRN em sintonia com 
a matriz nacional elaborada pela UFSC quando construiu a matriz nacional para os cursos da Rede e-Tec Brasil. (GOMES; GOMES, 2013, p. 11).

Concluindo a tentativa de catalogação das produções acadêmicas acerca da formação de professores para educação profissional e tecnológica a distância seguem as considerações finais.

\section{CONSIDERAÇÕES FINAIS}

É preocupante a ausência de produções acadêmicas acerca da problemática em questão e o silêncio que se percebe diante da quantidade de cursos e estudantes que vem se formando por meio dos cursos de ensino profissional e tecnológico a distância no Brasil.

Hipóteses acerca deste silenciamento? Algumas: a) o pouco período de tempo que os cursos de educação profissional e tecnológica a distância vêm sendo oferecidos em larga escala pela Rede Federal, já que até 2007, a oferta não era financiada e nem estimulada pelo poder público pode ser motivação para a redução das investigações científicas; b) o fato do ensino profissional e tecnológico a distância ter, historicamente, sido criado para atender aos interesses e às necessidades do mercado de trabalho, massificados e aligeirados, tanto para os estudantes, quanto para os professores, o que prejudica a compreensão do lugar de ambos no processo de ensinar e aprender; c) o desprestígio da modalidade de educação a distância, tida como destinada aos desafortunados; d) a forma de contratação docente, que não permite a criação de vínculo profissional e transforma a atividade profissional em um 'bico', não estimulando a pesquisa acadêmica e o interesse na ampliação das discussões acerca da temática.

Certezas observadas durante o exercício desta pesquisa? Poucas: a) percebe-se que a problemática da formação de professores sempre esteve presente nas pesquisas acadêmicas; $b$ ) observa a preocupação, embora timidamente, com a pesquisa para a formação professores para a educação profissional e tecnológica; c) as pesquisas acerca da formação de professores para a educação a distância ganharam destaque na última década.

A única produção acadêmica acerca da temática foi que localizada não aponta se é fruto de alguma pesquisa de Pós-Graduação Stricto Sensu e, os dois maiores repositórios de Teses e Dissertações do país não indicam, em 6 anos de pesquisa, a existência de produções acadêmicas que tratem, de forma sistematizada, dos descritores 'Educação Profissional e Tecnológica' e 'Formação de Professores' e 'Educação a Distância'.

Sendo assim, é urgente que a comunidade acadêmica volte seus olhos para necessidade de pesquisar sobre a temática, discutindo, teorizando e propondo alternativas para esta modalidade de educação, anunciada como alternativa para a formação integral de sujeitos em um país de dimensão continental como o Brasil.

\section{REFERÊNCIAS}

1. ALARCÃO, I. Formação Continuada como Instrumento de Formação Docente. In: VEIGA, I (org.) Caminhos da Profissionalização do Magistério. Campinas, SP: Papirus, 1998.

2. BRASIL. Lei no 11.892 , de 29 de dezembro de 2008. Disponível em: <http://www.planalto .gov.br/ccivil_03/_Ato2007-2010/2008/Lei/L11892.htm>. Acesso em: 28 jan. 2015. 
3. BRASIL. Lei $n$ o 9.394, de 20 de dezembro de 1996. Disponível em <http://www.planalto.gov .br/ccivil_03/Leis/L9394.htm>. Acesso em: 28 jan. 2015.

4. BRASIL. Decreto no 630, de 12 de dezembro de 2007. Disponível em: http://www.planal to.gov.br/ccivil_03/_Ato2007-2010/2007/Decreto/D6301.htm. Acesso em: 06 jun. 2015.

5. BRASIL. Decreto no 7589, de 26 de outubro de 2011. Disponível em: <http://www.planalto .gov.br/ccivil_03/_Ato2011-2014/2011/Decreto/D7589.htm>. Acesso em: 06 jun. 2015.

6. FLICK, U. Desenho da pesquisa qualitativa. Porto Alegre: Artmed, 2009.

7. GOMES, E. P. F; GOMES, H. R. A Formação Pedagógica e a Formação em Educação Profissional e Tecnológica de Tutores da Rede E-Tec Brasil no IFRN. Disponível em: <http://portal.ead.ifrn.edu.br/wp-content/uploads/2012/coloquio/anais/eixo3/Edilene\% 20Pereira\%20Ferreira\%20Gomes\%20.pdf> . Acesso em: 06 jun. 2015.

8. HADDAD, S. Juventude e escolarização: uma análise da produção de conhecimentos. Brasília/DF: MEC/Inep/Comped, 2002.

9. LITWIN, E.(org). Educação a Distância: Temas para Debate de uma Nova Agenda Educativa. Porto Alegre, Artmed, 2001.

10. MASETTO, M. Professor Univeristário: um profissional da educação na atividade docente. In: MASETTO, M. T. (Org.). Docência na universidade. Campinas: Papirus, 1998.

11. NÓVOA, A. (Coord.). Os professores e a sua formação. 2 ed. Lisboa: Dom Quixote, 1995.

12. OLIVEIRA, F. C. P.; SILVA, C. S. da. Ensino médio integrado à profissionalização: os desafios para a formação docente. In: II Seminário Nacional de Educação Profissional e Tecnológica - SENEPT. Minas Gerais: CEFET-MG, 2010. Disponível em: http://www.senept.cefet mg.br/galerias/Anais_2010/Artigos/GT8/FORMACAO_PEDAGOGICA.pdf. Acesso em: 07 jun. 2015.

13. PIMENTA, S. G. (Org.). Saberes pedagógicos e atividade docente. São Paulo: Cortez, 1999.

14. TARDIF, M. Saberes docentes e formação profissional. Petrópolis, RJ: Vozes, 2007.

15. THERRIEN, J. A natureza reflexiva da prática docente: elementos da identidade profissional e do saber da experiência docente. Educação em debate. Fortaleza, Ano 19, n. 33, 1997. 